EPJ Web of Conferences 45, 01122 (2013)

DOI: $10.1051 /$ epjconf/20134501122

(c) Owned by the authors, published by EDP Sciences, 2013

\title{
Measurement of Moisture Transport in the Membrane-Based Enthalpy Exchanger
}

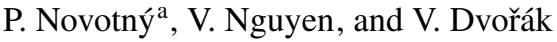 \\ Technical University of Liberec, Department of Power Engineering Equipment, Studentská 2, 461 17, Czech Republic
}

\begin{abstract}
Application of moisture membrane system can increase the efficiency of the HVAC system where the latent heat load is responsible for a large fraction of total energy. The moisture transfer mechanisms in membranes were studied on our experimental device, which supplied dry air and humid air in two regime. The dry air and humid air were delivered to membrane-based enthalpy exchanger with two contraflow cavities separated by the examined membrane. Nine types of hydrophilic membranes were compared by efficiency of moisture transport during isothermal humidity transport for flow velocity from 0.5 to $4 \mathrm{~m} \mathrm{~s}^{-1}$.
\end{abstract}

\section{Hydrophilic membranes}

Membrane can be defined as a barrier which restricts transfer of various substances from one side to other and only allows certain substances to permeate through it. The membrane discriminate between the various types of molecules because of differences in size, shape or chemical structure.

The performance or efficiency of a given membrane is determined by two parameters; its selectivity and the flow through the membrane. These materials have been extensively exploited for use in broad range of applications such as separation and purification, microfiltration and ultrafitration are membrane filtration processes commonly used in water treatment [1], gas separation, bioprocess membrane technology [2] and outerwear materials.

The chemical and physical properties of synthetic membranes and separated particles as well as a choice of driving force define a particular membrane separation process. Membranes structure can be homogeneous or heterogeneous with passive transport driven by pressure, concentration or a temperature difference [3].

\subsection{Molecular diffusion}

The most commonly used driving forces of a membrane process for the transporting of vapor molecules are pressure and concentration gradients. This net flux of molecules from region of higher concentration to one of lower concentration is called molecular diffusion. Molecular diffusion is typically described mathematically using Fick's first law of diffusion under the assumption of steady state [4]

$$
J=-D \frac{\partial \phi}{\partial x},
$$

where $J$ is the diffusion flux $\left(\mathrm{mol} \mathrm{m}^{-2} \mathrm{~s}^{-1}\right)$ per unit area and time, $\mathrm{D}$ is the diffusion coefficient in dimension of $\left(\mathrm{m}^{2} \mathrm{~s}^{-1}\right)$ and $\phi$ in $\left(\mathrm{mol} \mathrm{m}^{-3}\right)$ is the concentration in the position $x(\mathrm{~m})$ of the solute flow. Diffusivity $D$ depends on the absolute temperature, viscosity and the size of the particles in the fluid.

\subsection{Moisture transfer}

In this study the moisture transfer mechanism in the examined hydrophilic membranes are evaluated by efficiency of humidity transport. The hydrophilic membrane has ability to transport the water vapor (diameter of $\mathrm{H}_{2} \mathrm{O}$ molecule is about $0.28 \mathrm{~nm}$ ) from the humid air stream through the membrane to drier stream which is illustrated in figure 1 . Thin membrane has small heat transfer resistance and allows heat and moisture transfer simultaneously, but isothermal process $(\Delta T=0)$ was ensured during the measuring.

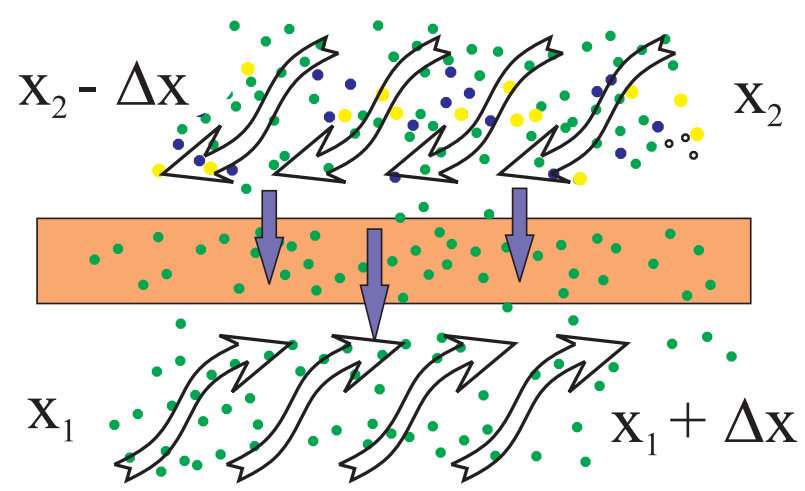

Fig. 1. Illustration of moisture (•) transfer through the hydrophilic membrane.

Two contraflow air streams are shown in figure 1, the "dry" and the "humid" flow in parallel separated by membrane layer, in order to transfer moisture $\Delta x$ from one air stream to the other. Where $x$ is the specific humidity in $\left(\mathrm{kg}_{\mathrm{v}} \mathrm{kg}_{\mathrm{d}}^{-1}\right)$ the mass of water vapor per unit mass of air. The transfered and received humidity should be the same quantity for equable flow rates during isothermal moisture transfer. With this assumptions we can write amount of the vapor which is transfered during the flow in membrane system [5]

$$
\dot{m}_{v}=\dot{V} \rho_{\mathrm{d}}\left(x_{\mathrm{o}}-x_{\mathrm{I}}\right) \text {, }
$$


where $\dot{V}$ is the volumetric rate of the air with partial density $\rho_{\mathrm{d}}, x_{\mathrm{o}}$ and $x_{\mathrm{i}}$ are specific humidity of the air in outlet and inlet of the humidity exchanger, respectively.

Psychometric properties of air-water vapor mixtures can be determined by the dry-bulb temperature $T$ and relative humidity $\varphi$ of the air with barometric pressure $p_{\mathrm{b}}$. Two corresponding state changes of air flows are shown in the schematic Mollier diagram in figure 2. The Mollier diagram is a graphic representation of the relationship between air temperature $T$, moisture content $(\varphi, x)$ and enthalpy $h$ for one kilogram of the dry air.

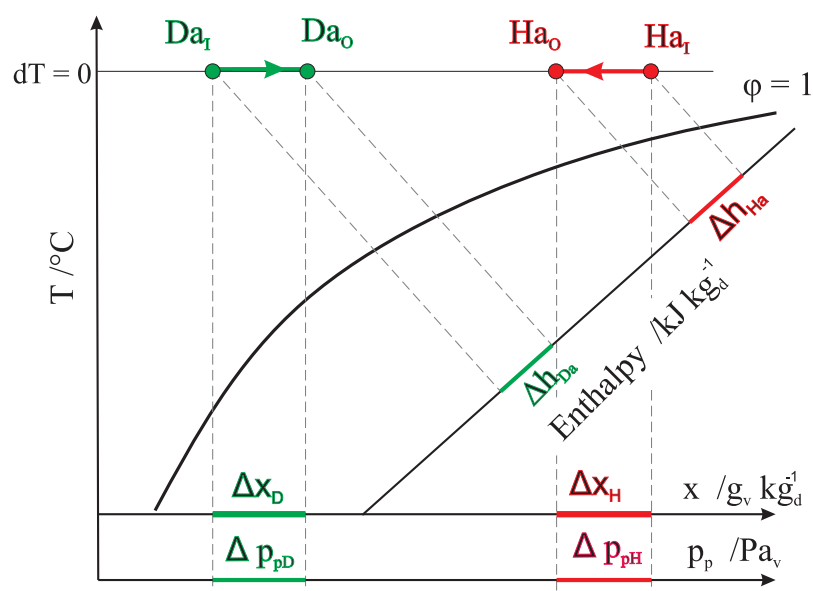

Fig. 2. The Mollier diagram with ideal moisture transfer

The moisture transport process of air can be expressed in a psychrometric chart, the change of "dry" air is defined by $\mathrm{Da}_{\mathrm{I}}$ to $\mathrm{Da}_{\mathrm{O}}$ and the "humid" air by $\mathrm{Ha}_{\mathrm{I}}$ to $\mathrm{Ha}_{0}$ with the same change of the amount of specific humidity $\Delta x_{\mathrm{D}}=\Delta x_{\mathrm{H}}$ and specific enthalpy $\Delta h_{\mathrm{Da}}=\Delta h_{\mathrm{Ha}}$ of the air flows. Changes of partial pressure of water vapor and relative humidity are approximately $\Delta p_{\mathrm{pD}} \approx \Delta p_{\mathrm{pH}}$ and $\Delta \varphi_{\mathrm{pD}} \approx \Delta \varphi p_{\mathrm{pH}}$, respectively.

The total pressure of moist air is expressed as $p_{\mathrm{b}}=$ $p_{\mathrm{d}}+p_{\mathrm{p}}$, where $p_{\mathrm{d}}$ is partial pressure of dry air and $p_{\mathrm{p}}$ is partial pressure of water vapor. The change of the specific humidity $x$ is directly proportional to the change of partial pressure of water vapor $p_{\mathrm{p}}$ and relationship is expressed as [6]

$$
p_{\mathrm{p}}=\frac{p_{\mathrm{b}} x}{0.622+x}
$$

Relative humidity $\varphi=p_{\mathrm{p}} / p_{\mathrm{p}}^{\prime \prime}$ is a ratio of the partial pressure of water vapor $p_{\mathrm{p}}$ in an air-water mixture to the saturated vapor pressure of water $p_{\mathrm{p}}^{\prime \prime}$ at a given temperature. The relative humidity of air depends not only on temperature but also on the pressure of the system of interest $p_{\mathrm{b}}$. Then the specific humidity $x$ is calculated as

$$
x=0.622 \frac{p_{\mathrm{p}}}{p_{\mathrm{b}}-p_{\mathrm{p}}}=0.622 \frac{\varphi p_{\mathrm{p}}^{\prime \prime}}{p_{\mathrm{b}}-\varphi p_{\mathrm{p}}^{\prime \prime}},
$$

where constant was established by the ratio of specific gas constant of dry air $r_{\mathrm{d}} \doteq 287 \mathrm{~J} \mathrm{~kg}^{-1} \mathrm{~K}^{-1}$ and water vapor $r_{\mathrm{v}} \doteq 461.5 \mathrm{~J} \mathrm{~kg}^{-1} \mathrm{~K}^{-1}$. The saturated vapor pressure for temperature range $0{ }^{\circ} \mathrm{C} \leq t \leq 80^{\circ} \mathrm{C}$ is approximated by [6]

$$
p_{\mathrm{p}}^{\prime \prime}=\exp \left(23.58-\frac{4044.6}{235.63+t}\right)
$$

\subsection{Enthalpy of Water Vapor}

The transport of sensible heat is generally present in common recovery heat exchangers with impermeable walls. Reuse of latent heat occurs only under condensation conditions on the heat transfer surface with the local temperature under the dew point. Applications with moisture membrane system would increase the efficiency of the HVAC system where the latent heat load is responsible for a large fraction of the total load of air-conditioning. Specific enthalpy of moist air can be expressed as $h=h_{\mathrm{d}}+x h_{\mathrm{v}}$, where $h_{\mathrm{d}}$ is specific enthalpy of dry air and $h_{\mathrm{v}}$ is specific enthalpy of water vapor in $\left(\mathrm{J} \mathrm{kg}^{-1}\right)$. Specific enthalpy of dry air for constant pressure is $h_{\mathrm{d}}=c_{\mathrm{pd}} t$ and $c_{\mathrm{pd}} \doteq 1.01 \mathrm{~kJ} \mathrm{~kg}^{-1} \mathrm{~K}^{-1}$ is specific heat capacity of dry air with temperature $t$ which could be defined zero enthalpy $\left(0 \mathrm{~kJ} \mathrm{~kg}^{-1} \mathrm{~K}^{-1}\right.$ at $\left.0{ }^{\circ} \mathrm{C}\right)$. The latent heat of moist air is specified by enthalpy of water vapor [6]

$$
h_{\mathrm{v}}=c_{\mathrm{pv}} t+l_{0},
$$

where $c_{\mathrm{pv}}$ is specific heat of water vapor at constant pressure and $l_{0}=2257 \mathrm{~kJ} \mathrm{~kg}_{\mathrm{v}}^{-1}$ evaporation heat of water at $0{ }^{\circ} \mathrm{C}$, then we can write expression for overall specific enthalpy as

$$
h=h_{\mathrm{d}}+x h_{\mathrm{v}}=c_{\mathrm{pd}} t+x\left(l_{0}+c_{\mathrm{pv}} t\right) .
$$

The latent part of energy $x l_{0}$ is not usually utilized in common recovery heat exchangers, which were examined in the previous investigation $[7,8]$. Enthalpy exchangers should transport certain part of latent energy $\Delta x l_{0}$ through hydrophilic porous membrane without phase change.

\section{Evaluation procedure}

Temperature of changes were insignificant during the measuring period of 60 seconds, when four sensors recorded temperature $t$, relative humidity $\varphi$, dew-point $t_{\mathrm{d}}$ and absolute pressure $p_{\mathrm{b}}$ every five seconds. The most important operation before sampling data was stabilization of both air flows at the same volume flow rate (see figure 3, positions (8) and (9)) by two reduction valves (6). With these conditions and simplification $\Delta \varphi_{\mathrm{pD}} \approx \Delta \varphi p_{\mathrm{pH}}$ we can establish efficiency and its error of moisture transport $\eta_{\% \mathrm{RH}}$ only by relative humidity differences from both flows as

$$
\eta_{\% \mathrm{RH}}=0.5 \frac{\left|\Delta \varphi_{\mathrm{Ha}}\right|+\left|\Delta \varphi_{\mathrm{Da}}\right|}{\varphi_{\mathrm{Da}_{\mathrm{I}}}-\varphi_{\mathrm{Ha}_{\mathrm{I}}}} \times 100
$$

and its measurement error

$$
\text { \%error }=2 \frac{\Delta \varphi_{\mathrm{Ha}}+\Delta \varphi_{\mathrm{Da}}}{\left|\Delta \varphi_{\mathrm{Ha}}\right|+\left|\Delta \varphi_{\mathrm{Da}}\right|} \times 100
$$

which is sensitive to difference of the flow rates, any air leakage and accuracy of sensors as well. Error in measurement is inversely proportional to the magnitude of volume flow rate and the highest instability up to $35 \%$ was monitored for 200 liters per hour of volume flow rates. 


\section{Experimental arrangement}

In the figure 3, experimental pipeline arrangement is depicted. Source of compressed dry air $(<7 \% \mathrm{RH})$ delivered air to T-junction (4), where was divided to "dry" and "humid" way. For volume flow measurement, two rottameters $(8,9)$ were used with range from 0 to 20001 hod $^{-1}$. Volume flow rates were regulated by reduction valves (6) separately. The moisturize way was eqquiped with water tank (7) where it was possible to switch flow of air above water level (40-65\%RH) or under water (60-80\%RH). The same volumetric flow rate was dellivered to experimental enthalphy exchanger with tested memranes $(10,11)$.

Four sensors FHAD36RS Ahlborn were mounted in inlets (I) and outlets (o) knees. Relative humidity $\varphi$, bulb temperature $t$, dew point temperature $t_{\mathrm{d}}$ and total pressure $p_{\mathrm{b}}$ were scaned by ALMENO 2590-4S data logger and sent to personal computer. Data processing was analysed in own MATLAB code.

Two cavities of experimental exchanger had cross section area of $2.15 \times 80 \mathrm{~mm}$ are separated by tested membrane and were dived by two ribs $(10 \mathrm{~mm})$ in main flow direction which should have equilibrated flow around the membrane. Final velocity is computed by $v=\dot{V} / S$, where $S$ is resulting cross section area of cavities. The length of cavities were $200 \mathrm{~mm}$.

\section{Experimental results}

Nine different membranes were experimentally tested. The tested materials were obtained directly from manufacturing companies. Most of them were based on thermoplastic elastomer (TPE) materials. Two were anisotropic type and tested from both sides $(\mathrm{Sa}, \mathrm{Sc})$. Two membranes (K1, $\mathrm{K} 2$ ) are made from sulfonated styrenic copolymer material with support based on cellulose substrate.

In figure 4, we can see results of our measuring. Effect of transporting of the water vapor through membranes is obvious. The higher efficiencies were obtained for regimes with sulfonated samples.

Anisotropic membrane ( $\mathrm{Sa}$ ) has surprisingly effect on performance which depends on the placing of matte side on the humidity air flow. The effect of second anisotropic membrane $(\mathrm{Sc})$ was not appreciable. The best one sample(P) was from industrial manufactured company which used this membrane also for enthalpy heat exchanges.

Table 1. Table of tested hydrophilic membranes

\begin{tabular}{c|cc} 
name of sample & membrane type & specification \\
\hline $\mathrm{K} 1$ & isotropic & sulphonate \\
$\mathrm{K} 2$ & isotropic & sulphonate \\
$\mathrm{P}$ & isotropic & technical \\
$\mathrm{E}$ & isotropic & $15 \mu \mathrm{m}$ \\
$\mathrm{T}$ & isotropic & technical \\
$\mathrm{Sa}$ & anisotropic & $55 \mu \mathrm{m}$ \\
$\mathrm{Sb}$ & isotropic & $55 \mu \mathrm{m}$ \\
$\mathrm{Sc}$ & anisotropic & outerwear \\
$\mathrm{Sd}$ & isotropic & outerwear \\
$\mathrm{Se}$ & isotropic & outerwear \\
\hline
\end{tabular}

\section{Conclusion}

Experimental device was built in order to test different type of hydrophilic membranes (see table 1). In this study, system of experimental arrangement with membrane-based enthalpy exchanger were shown. Membrane materials, which are usually hydrophilic porous desiccants, have large impacts on the performance of enthalpy exchangers.

For reducing of energy consumption in residential building, a heat recovery system must be applied. We have focused on sensible heat recovery, and we have ignored latent heat. But there are two reasons to care about latent heat which is related to humidity obtained in the air:

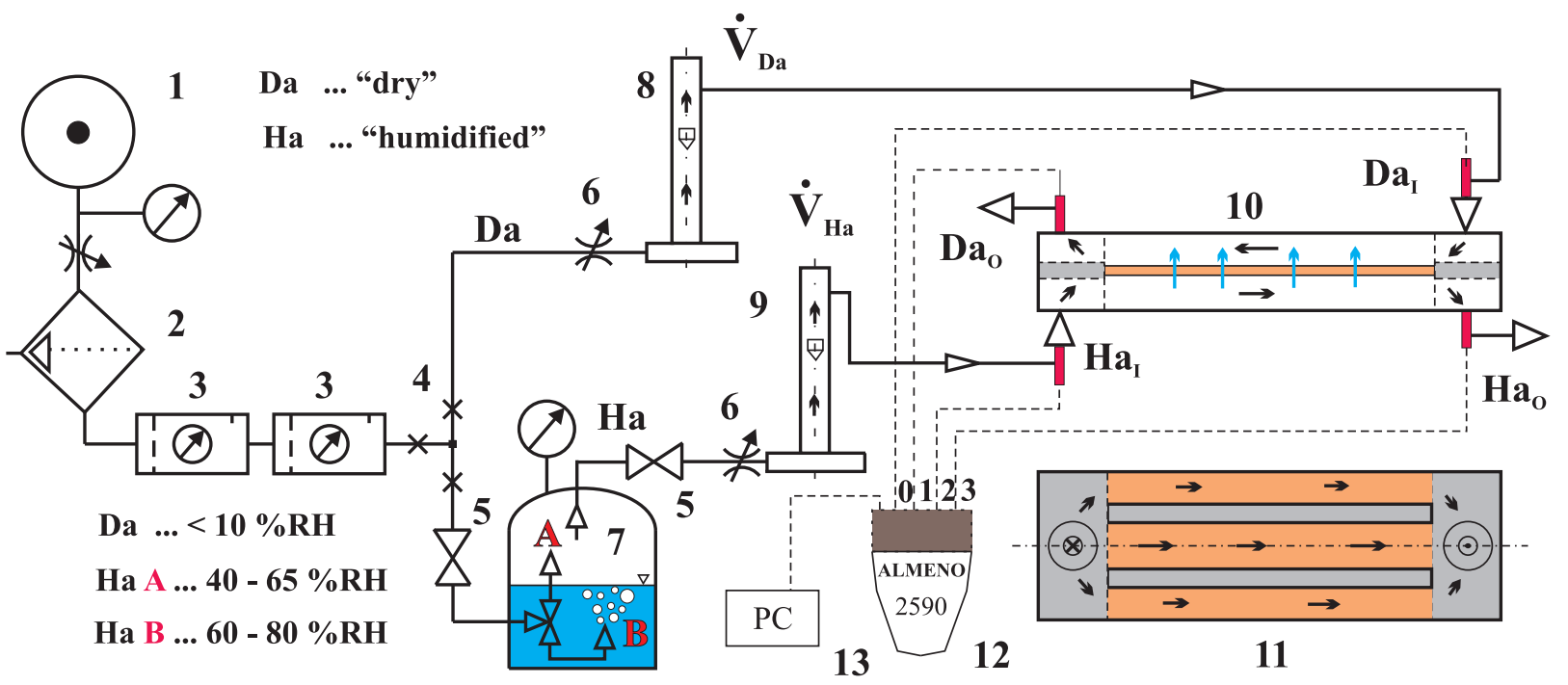

Fig. 3. Experimental arrangement: 1 - source of compressed dry air, 2 - separator filter, 3 - pressure regulator, 4 - T-junction to "dry" and "humidified" way, 5 - closing valve, 6 - reduction valve, 7 - two intensity modes humidifier, 8 - rotameter "dry", 9 - rotameter "humidified", 10 - experimental enthalpy exchanger (ground plan), 11 - side view of experimental enthalpy exchanger, 12 - ALMEMO 2590-4S data logger, 13 - PC (AMR-CONTROL software) 


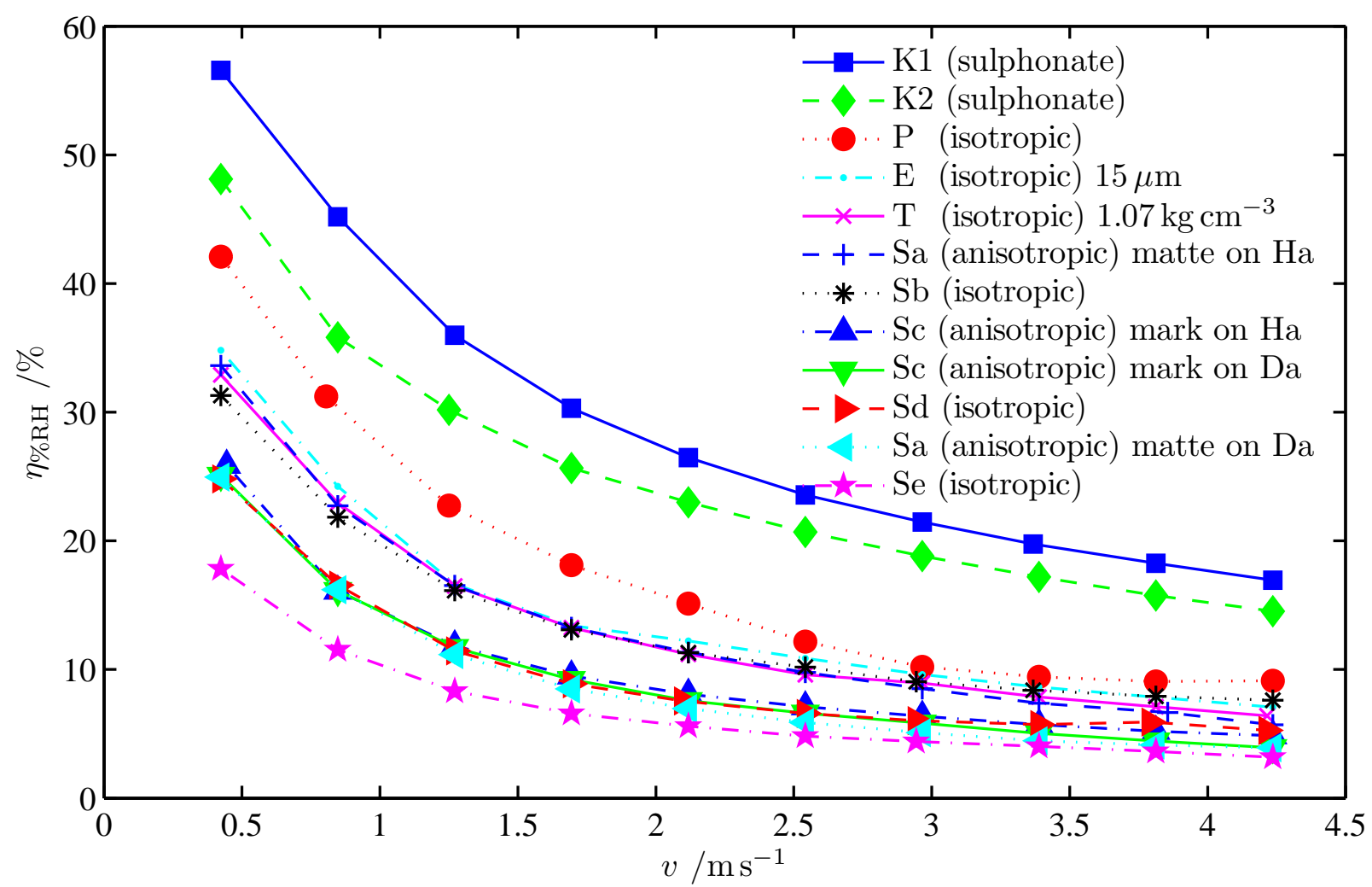

Fig. 4. Graph of efficiency vs velocity for every tested membranes

In a heated space (in winter), the humidity drops significantly (to about 20-40 \% RH) and it leads to uncomfortable feeling for people who are living there.

Secondly, humidity contains great amount of energy which is the latent heat so the loss of humidity in the heated area means a loss of energy.

We can solve these problems by using membrane-based exchangers. In this article, we tried to figure out properties of some certain membranes and make comparison of efficiency of moisture transfer for different mass flow rates between them. The research will continue with other samples of membranes. Deeper knowledges about water vapor transport are expected.

\section{Acknowledgments}

This project was realized with financial support by the Technological Agency of the Czech Republic, No. TA01020313.

\section{References}

1. M. Peter-Varbanets, C. Zurbrugg, C. Swartz, W. Pronk, Water Research 43, 245 (2009)

2. R. van Reis, A. Zydney, Journal of Membrane Science 302, 271 (2007)

3. M. Mulder, Basic Principles of Membrane Technology (Kluwer Academic Publishers, Netherlands, 1996)

4. R.B. Bird, W.E. Steward, E.N. Lightfoot, Transport Phenomena, 2nd edn. (John Wiley and sons, 2002)

5. M. Vestfalova, Evaluation of material properties determining the moisture transfer, in Experimental Fluid Mechanics (2012)

6. S. Marta, K. Ferstl, R. Novy, Vetrani a klimatizace (Jaga, Bratislava, 2006)

7. P. Novotny, Numerical Simulations of Recovery Heat Exchangers, in Engineering Mechanics (2010), Vol. 17, pp. 439-442

8. P. Novotny, Master's thesis (2010) 